\section{Información, comunicación y equidad: dilemas en el ámbito sanitario}

Fernando Lolas ${ }^{1}$
El concepto de equidad está ligado estrechamente con el de justicia, que a su vez adopta diferentes formas. Se habla de justicia conmutativa cuando en las relaciones, especialmente las de naturaleza contractual, las partes acuerdan retribuirse proporcionada y apropiadamente lo que intercambian. El "honorario" por las prestaciones médicas, por ejemplo, es una forma de denominar una compensación que, debido a la naturaleza "impagable" del servicio prestado (restaurar la salud o salvar la vida), no solamente se hace con dinero sino también con honor y aprecio. Suele hablarse de justicia distributiva cuando los bienes de los que dispone una comunidad se reparten de tal modo que los semejantes son tratados como semejantes y la "ceguera" de la norma o tradición, esto es, la aplicación acrítica y automática de la regla universal, se compensa con la prudencia. Puesto que se reconoce que las personas son desiguales en numerosos ámbitos, la prudencia indica que las desigualdades que son injustas por ser evitables, innecesarias o intencionadas deben ser compensadas y "equiparadas". La equidad es, por ende, la forma de justicia más apropiada (1). No supone un igualitarismo ciego, sino una igualdad que sea valiosa para la vida y la dignidad humanas, de las que se dice que aunque tienen valor, no tienen precio. Son atributos intransables de la condición moral de los seres humanos y compete a las profesiones que tratan con ellos acrecentar la conciencia ética de las comunidades, es decir, la moral reflexionada y justificada por principios universales.

\section{EQUIDAD DEL ACCESO A LA INFORMACIÓN Y COMUNICACIÓN}

No cabe duda de que la información es un bien (commodity) que repercute en el bienestar de las personas. La relación no es sencilla, sin embargo. Las primitivas formulaciones del desarrollo, populares hace algunos lustros, fundamentaban la necesidad de la investigación científica porque más conocimientos significaban más riqueza y más riqueza implicaba una mayor felicidad. El lema positivista de "ver para prever, prever para proveer" equipara la cantidad de información con una mayor capacidad para superar problemas, que a su vez redunda en mayor satisfacción humana. El concepto del "desarrollo" suplantó al del "progreso", que el positivismo clásico postuló como meta de la humanidad. Las "etapas" del progreso científico y moral
Palabras clave: equidad, información, comunicación.

\footnotetext{
Programa Regional de Bioética de la Organización Panamericana de la Salud, Washington, D.C., Estados Unidos de América. Dirección postal: Providencia 1017, Piso 7, Santiago de Chile. Correo electrónico: lolasf@chi.ops-oms.org
} 
debían ser cumplidas por todas las sociedades de manera relativamente uniforme. Aun reconociendo que algunas sociedades desarrolladas (por definición más ilustradas y más felices) han cometido algunos errores que las que están en desarrollo podrían conocer y evitar, a las primeras se las presenta como el desideratum de la perfección humana y el modelo que debe emularse.

Muchas de las presunciones en que se basa este punto de vista son discutibles en un sentido lógico y ético. En primer lugar, la secuencia información-riqueza-bienestar está lejos de ser convincente, entre otras razones porque la información es solo uno de los constituyentes del conocimiento, el cual se caracteriza más por la estructura y el ordenamiento de la información que por su cantidad. El conocimiento es información organizada en torno a intereses y valores sociales. No puede afirmarse que las sociedades más desarrolladas sean aquellas donde predomina el conocimiento. Aun en las más complejas y evolucionadas, o en las mejor "alfabetizadas", hay ignorancia, prejuicio, superstición e ideas primitivas. El conocimiento no está uniformemente distribuido en la población, de modo que la capacidad para utilizarlo y ampliarlo no es homogénea ni uniforme.

Tampoco puede sostenerse que los valores que fundamentan el trato humano sean reconocidos y aceptados por todos los miembros de esas sociedades. Falta resolver en ellas dilemas perennes de la condición humana; hay disensiones internas, violencia e injusticia, desprecio por los derechos de las personas e insatisfacción.

La premisa de que la información se vincula con el bienestar debe, por ende, ser examinada desde un punto de vista antropológico amplio y puesta en relación con la acción social orientada hacia obtener algún valor. Ninguna "educación" a ciegas, sin metas sociales, produce de forma automática la deseada satisfacción o el esperado bienestar que los panegiristas del desarrollo ingenuamente han destacado. La equidad en materia de información pasa por reconocer que el conocimiento, que es información articulada, exige procesos de comunicación, en los cuales la praxis de las profesiones y las organizaciones profesionales debe tener activa participación.

La "praxis comunicativa" no debe confundirse con la comunidad de finalidades o metas de las decisiones estratégicas de los actores sociales, ni con el acatamiento de las normas o el comportamiento adecuado ("políticamente correcto") en las comunidades. Implica el reconocimiento mutuo de los individuos y los grupos como interlocutores válidos que, en el espacio provisto por los lenguajes simbólicos, aspiran a compartir cometidos (tareas), contenidos (datos e informaciones), conocimientos (estructura y organización de los datos) y respeto por la dignidad de los demás (2).

La diferencia entre grupos y personas en términos morales ("extraños en lo moral", en la expresión de Engelhardt) (3) se transforma en desigualdad epistémica cuando los datos y la información que se consideran relevantes o útiles se imponen sin tener en cuenta el campo comunicativo y los espacios semánticos en que ellos pueden tener "sentido". La imposición generalizante de un punto de vista es, de por sí, una manifestación de inequidad y una expresión de "imperialismo ético". Gran parte de la clásica "educación sanitaria" consistía en imponer el punto de vista del "experto" a poblaciones incapaces de asimilar la información y en las cuales, a menudo, la estructura del conocimiento "científicamente correcto" era ajena a sus hábitos de pensamiento y valores prioritarios. La literatura antropológica y etnológica suele documentar la distinción entre "dato" y "creencia" como una mezcla entre el poder del discurso técnico para imponer su "verdad" y formas legítimas de acceder a certidumbres. Por definición, la "creencia" es desvalorizada como irrelevante o trivial, sin atender al poder de las convicciones en el estado de salud. A menudo, la diferencia entre "creencia" y "dato" se basa en los procedimientos para su obtención o en la autoridad de la fuente. Finalmente, se trata de una contienda entre diferentes "discursos" con los que se aspira a articular y controlar la realidad (4).

\section{LA BIOÉTICA COMO DIÁLOGO SOCIAL CRÍTICO}

Uno de los adelantos más importantes de la ciencia de la comunicación consiste en haber superado la noción de que la comunicación es eficaz porque "transmite" algo al receptor. Más bien, la comunicación eficaz es aquella que se "internaliza" en las destrezas, actitudes y capacidades de este. La verdadera y legítima comunicación en el campo de la salud "selecciona" en quien la recibe aquellas conductas que son deseables para promover el bienestar.

En términos prácticos, esto significa que la comunicación de los que son expertos con los que no lo son precisa de varios requisitos para ser eficaz. En primer término, hace falta una motivación para promover la demanda de información. En segundo lugar, es necesario que el contenido y la forma de la información estén en proporción con la capacidad del receptor para comprenderlas e integrarlas armoniosamente a su conjunto previo de creencias, nociones y conocimientos. Finalmente, es preciso que haya posibilidades de usar los conocimientos, esto es, que lo aprendido redunde en una diferencia en términos prácticos. El "saber" y el "hacer" puros 
son insuficientes. Como en el caso de las profesiones y el conocimiento formal, todo conocimiento socialmente útil consiste en saber hacer algo (4).

El discurso bioético se ha caracterizado por haber hecho partícipes a todos los agentes y actores sociales en las decisiones que les conciernen. Entre ellas, las referidas a la salud son importantes, ya que no hay persona que no ocupe alguna vez en su vida el papel social de "enfermo". La natural asimetría de las relaciones entre expertos y profanos no debiera verse con ello alterada, pero sí modificada en un sentido positivo. Lo que los sistemas de cuidado de la salud debieran proveer a las personas se sintetiza en las palabras "curar", "sanar" y "cuidar", pero también en "habilitar" para el autocuidado y la formulación de expectativas realistas. Cualquiera que sea la evolución de las instituciones sanitarias, es de suponer que las cíclicas crisis por las que atraviesan podrían atenuarse si las demandas estuvieran en consonancia con sus ofertas verdaderas y no las que son falsas o desmedidas (5).

La equidad como valor social, que representa la forma practicable de la justicia, impregna la noción de que los avances de las ciencias y la tecnología deben colocarse a disposición de todos los actores y agentes sociales con finalidades consensuadas y en las formas apropiadas según su posición en el grupo social.

\section{LA COMUNICACIÓN CIENTÍFICA}

La responsabilidad profesional se relaciona con la información destinada a construir conocimientos generalizables. Como se ha señalado, estos no consisten en información solamente, sino más bien en la estructura que la dota de sentido social. No hay conocimiento neutral. La información puede articularse con fines estéticos, utilitarios, publicitarios o teóricos. El conocimiento es "información interesada" (la palabra inter-esse significa "entre seres"), es decir, que equivale a revelar vinculaciones entre personas o cosas. El conocimiento es lo que las instituciones académicas y universidades construyen, transmiten y atesoran. El conocimiento, no la información, es la sustancia del progreso de las disciplinas científicas. La mayoría de los profesionales del área de la salud basan sus afirmaciones y convicciones en conocimientos publicados. La ética de la publicación científico-técnica también exige responsabilidad y respeto. De allí deriva su legitimidad. La comunicación pública de un nuevo procedimiento diagnóstico o terapéutico debe hacerse solo después de comprobar su utilidad y eficacia. Impera en el campo biomédico la norma de que nada debe ser comunicado a los medios masivos si antes no ha sido consignado en re- vistas especializadas o al menos sometido al juicio de pares rigurosos (regla de Ingelfinger). De otro modo, se despiertan falsas expectativas y puede aprovecharse el estado de necesidad de las personas para lucrar o abusar (6).

Debe destacarse la integridad en la obtención y el manejo de los datos que sirven de base a la información y al conocimiento. Por ella se entiende no solamente la honradez que debe imperar en su obtención y comunicación, sino también la calidad de los medios que se usan. Aun aquellos datos que pueden ser útiles para el progreso de la ciencia pierden su carácter benéfico y se transforman en simples medios para obtener prestigio, dinero o poder, si fueron obtenidos mediante el engaño, la coacción o la falsedad. En este ámbito, no basta con respetar formalmente las declaraciones internacionales y las normas éticas, imperativos para publicar en revistas prestigiosas. Es necesario estar plenamente convencido de que respetarlas es condición intrínseca del carácter de un científico responsable, que elige no solamente un medio para obtener recompensas sociales sino un estilo de vida orientado a acrecentar el conocimiento (7).

\section{LA INFORMACIÓN PÚBLICA}

Los profesionales de la salud no constituyen la única fuente de información sanitaria. Esta se encuentra ampliamente diseminada, especialmente desde el advenimiento de los sistemas electrónicos de acceso fácil, como la Internet. Hay, por lo tanto, una industria de producción de datos e información que ha superado con creces la oferta de libros y revistas. Velar por la idoneidad de esta información es también responsabilidad de las instituciones y expertos en comunicaciones. Como en esas fuentes puede haber fines ajenos a la terapéutica y la ciencia (p. ej., el afán de lucro), el equilibrio adecuado debe basarse en los principios de beneficencia, justicia y ausencia de maleficencia, además del respeto a la autonomía ya mencionado. Para los médicos y otros profesionales sanitarios, la ausencia de maleficencia no debe entenderse solamente en relación con su actividad personal, sino que ha de extenderse a las actividades de otros. Un experto que considere que la información proporcionada por una fuente o un medio cualquiera no es idónea ni confiable, o que puede llevar a comportamientos inadecuados, debe manifestarlo y evitar así las falsedades o perjuicios a los que pueda dar origen dicha información. Por otra parte, es responsabilidad de los profesionales, en su búsqueda de la equidad en el campo de la información, conseguir que ella sea accesible en la medida en que las audiencias pueden entenderla. Este principio de proporcionalidad 
afecta al lenguaje en que la información se comunica y al tipo de información que se difunde, la cual debe aspirar a conseguir un beneficio máximo para el mayor número de personas, respetando sus patrones culturales y su bienestar.

No es necesario que los expertos se transformen en censores públicos de la información para que esta demanda ética se vea satisfecha. Su verdadera obligación es considerar de una manera global lo que mejor satisface el bienestar general. No consiste en rechazar la publicidad o los intereses comerciales o de otra índole, puesto que sería ilusorio negar la influencia del mercado en la vida contemporánea. Velar por el bien común y la fe pública en la comunicación que afecta a la salud es un imperativo universal y parte de la responsabilidad de los profesionales. La prudencia es aquella virtud que permite resguardar la cantidad y calidad de la información de salud que se destina al público, que debe ser lo suficientemente explícita como para ser útil y lo suficientemente cautelosa para no generar alarma innecesaria. Debe, en síntesis, promover el bienestar y ser parte de él.

\section{CONSIDERACIONES FINALES}

No existe ni el vacío ético ni la neutralidad moral. Científicos, técnicos, educadores y profesionales deben reconocer que todo su quehacer tiene un valor y una utilidad moral. Algunas de las más censurables acciones de grupos y personas se han debido a la errada creencia de que el conocimiento científico tiene un valor neutro. En la medida en que sus efectos o consecuencias afecten a las personas, eso es una equivocación.

Tal es el sentido del paradigma bioético en las ciencias y las disciplinas técnicas. La ciencia y sus aplicaciones son asuntos humanos $\mathrm{y}$, en virtud de ello, son acciones morales cuyos agentes tienen el carácter de agentes morales, esto es, personas conscientes y responsables de sus actos. La información, en sí misma, es un elemento necesario, pero no es suficiente para construir conocimientos. Una misma información puede ser utilizada en diversos contextos. Por ejemplo, puede servir para apoyar un argumento económico, fundamentar una acción terapéutica, zanjar una disputa teórica o ser parte de una elucubración filosófica. A partir de la información se construyen distintos tipos de conocimientos que tienen interés social y su propia retórica de producción y transmisión. El conocimiento científico debe su hegemonía a las formas aceptadas de obtenerlo, a la autoridad de la tradición que corporiza y a su eficacia en el plano práctico. La equidad en el acceso al conocimiento no consiste, por lo tanto, en propalar informaciones útiles o verdade- ras, sino en reformularlas según el contexto de quienes van a recibir dicho conocimiento. Ello impone un modo especial de aproximarse, el de tipo comunicativo, que no consiste simplemente en difundir, sino en establecer con quienes reciben el conocimiento un diálogo prudente, dándole a cada participante la posibilidad de incorporar lo nuevo en el contexto de sus experiencias anteriores, su cultura peculiar, sus valores tradicionales. Aunque ello rige especialmente en el campo de la comunicación pública y en la relación entre expertos y legos, también debe tenerse presente en las relaciones entre tradiciones científicas disímiles, entre científicos de culturas distintas y en la necesaria relación del discurso científico con otras prácticas sociales, como la economía y el derecho. Si la equidad se entiende solamente como la posibilidad de acceder a la información, se pierde su carácter esencialmente moral, que es la justicia en el respeto a la diversidad: tratar a los semejantes como semejantes y a los no semejantes como no semejantes. Para ello hay que comprender profundamente la comunicación como participación y como respeto a la dignidad de las personas, la cual impone deberes y derechos.

Es posible argumentar que un aspecto importante del debate sobre la equidad y la comunicación debiera gravitar en torno a la disponibilidad de los medios técnicos adecuados para acceder a las nuevas formas de información. Se habla, con razón, de la brecha digitálica (digital divide), que separa a los que tienen (haves) de los que no tienen (have nots) en materia de información electrónica. Sin duda, se trata de un aspecto que merece atención. En las ciencias y las técnicas que afectan al bienestar de las personas parece operar el famoso principio de Mateo: "a los que tienen, se les dará". Se sabe que un científico que ha publicado un trabajo tiene más probabilidades de publicar otro que uno que nunca ha publicado nada, y esta probabilidad aumenta con el número de publicaciones. Quienes ya poseen acceso a la Internet suelen conocer nuevas formas de mejorar su acceso precisamente mediante los propios recursos de la red electrónica, de modo que la tendencia "natural" de los sistemas tecnocráticos es a acrecentar, no a reducir, las desigualdades. Es probable que lo mismo se aplique a cualquier otro recurso y, sin duda, el ejemplo más divulgado se refiere a los sistemas sanitarios. Hasta ahora, no es convincente el argumento de que quienes tienen debieran renunciar a parte de lo que poseen para que otros también lo tengan, pues las nociones de necesidad y el principio de justicia como equidad no concitan adhesión universal ni pueden imponerse por la fuerza.

Es posible que el principio de que "quienes más tienen más pueden" no se aplique, a manera de excepción, a la comunicación genuina de aquellos 
conocimientos que suponen mejoras del estado de salud y bienestar. Siendo el conocimiento algo distinto de la información, es concebible que se pueda cerrar la brecha que separa a los grupos humanos mediante una prudente reformulación y un esfuerzo por parte de profesionales comprometidos con la causa de la equidad en el saber. Porque saber siempre equivale a compartir. El conocimiento que no se comparte degrada a quienes lo tienen tanto como a quienes no lo tienen. Si los medios fallan, se deberá procurar que sean uniformes en el futuro y suplir su deficiencia con el esfuerzo, la buena disposición y la excelencia que deben presidir en el ejercicio de las profesiones sanitarias.

Buena parte de la labor para el futuro deberá consistir no solamente en acrecentar los medios técnicos y ponerlos a disposición de todos, sino también en buscar formas de construir conocimientos que puedan compartirse aun cuando no se dispone de tecnologías costosas. Hablar a cada uno de los agentes y actores sociales en su lengua significa res- petar, en el plano de la comunicación, la equidad del conocimiento útil.

\section{SYNOPSIS}

\section{Information, communication, and equity: dilemmas in health}

Equity, which is a form of justice, is the absence of inequalities that are evitable or unjust or that stem from preventable causes. In the area of health, it is linked to prudence that should prevail in the exercise of the health professions. Information, like any other social commodity, can be distributed in an inequitable way among different groups or populations due to technological barriers or cultural factors. However, knowledge is not just information; it is information that is aimed at a specific social purpose. Inequity in knowledge can be reduced by means of genuine communication, as Habermas proposed. This article deals with scientific communication as much as it does with public knowledge and the way information is disseminated.

\section{REFERENCIAS}

1. Rawls. J. Una teoría de la justicia. $2^{\mathrm{a}}$ edición en español. México, D.F.: Fondo de Cultura Económica; 1995.

2. Habermas J. Zur theorie des kommunikativen Handelns. Frankfurt: Suhrkamp Verlag (edition Suhrkamp); 1988.

3. Engelhardt T. Los fundamentos de la bioética. Barcelona: Paidós; 1995.
4. Lolas F. Más allá del cuerpo: la construcción narrativa de la salud. Santiago (Chile), Buenos Aires, México, D.F.: Editorial Andrés Bello; 1997.

5. Lolas F. Bioética y antropología médica. Santiago, Chile: Editorial Mediterráneo; 2000.
6. Lolas F. Proposiciones para una teoría de la medicina. Santiago, Chile: Editorial Universitaria; 1992.

7. Lolas F. Etica de la publicación médica: legalidad y legitimidad. Acta Bioethica 2000; 6(2):283-291. 